Sex determination techniques have diffused rapidly in India, and are being used to detect female fetuses and subsequently to abort them. This technology has spread rapidly because it imparts knowledge that is of great value within the Indian context, and because it fits in neatly with the modernization dynamic within India, which itself has enmeshed with traditional patriarchal institutions to oppress Indian women. More research needs to be done on ways to stem the adoption of problematic innovations.

\title{
A Case of Problematic Diffusion
}

\author{
The Use of Sex Determination Techniques in India
}

\section{RASHMI LUTHRA}

University of Michigan

The 1970s have been characterized as an era of "introspective criticism for diffusion research" (Rogers 1983, 91), as well as a period of denigration of the dominant paradigm of Third World development, including the dominant paradigm's communication approach (Melkote 1991). The 1980s saw a move toward formulating alternative conceptions of development, and communication in development, and trying to create changes in practice based on a newly developing vision. The 1980 s have also been marked by the beginnings of gender-sensitive research in development (Melkote 1991, 18).

Some crucial aspects of the paradigm shift include a reevaluation of the causes and consequences of development, underdevelopment, and modernization. This reevaluation has included a questioning of the dichotomy between tradition and modernity, and has denied the earlier notion of tradition

\footnotetext{
Author's Note: I am very grateful to Manju Parikh for the inspiration and materials for this article. I am also grateful to the Forum against Sex Determination and Sex Preselection, particularly Sonal Shukla and Vibhuti Patel of the Forum, whose research and activism are the basis for this article. Thanks go to Everett Rogers and Hemant Shah for their feedback on an earlier draft of the article.
}

Knowledge: Creation, Diffusion, Utilization, Vol. 15 No. 3, March 1994 259-272

C 1994 Sage Publications, Inc. 
as the problem and of modernization as the solution. A central insight of the newer approaches has been that tradition and modernity may mesh quite well to serve the interests of the powerful, and that "quite often, the perpetuation of the traditional setup served the interests of the modern sector" (Melkote 1991, 140).

Within the diffusion-of-innovations field, there has been a move away from blaming the victim of underdevelopment to examining the structural constraints that keep individuals from adopting innovations. Similarly, there has been a shift from the exclusive emphasis on the individual as the locus of decision making toward regarding the family and other groups as influential in adoption decisions (Melkote 1991; Rogers 1976). Echoing the larger recognition of the contradictory effects of modernization, there has been a recognition of the contradictory effects of the diffusion of particular innovations, chief among these the widening of socioeconomic and communication gaps between the haves and the have-nots (Roling, Ascroft, and Chege 1976). Furthermore, it has been acknowledged that diffusion research has been particularly weak in examining the long-term and unintended consequences of supposedly beneficial innovations and that it has focused almost exclusively on short-term, after-the-fact evaluations of the adoption of successful innovations (Rogers 1983).

My focus here on the rapid diffusion of a technology that clearly has contradictory implications within the Indian context is an attempt to further reconceptualize diffusion. This case of diffusion defies easy generalizations, and forces a questioning of various constructs, including "innovation," "innovativeness," and the role of tradition and modernity in the adoption of innovations within a particular sociocultural context. Moreover, my analysis of the diffusion of sex determination tests forces the inclusion of gender as a necessary analytical construct. Earlier critiques of diffusion research have directed attention to the influence of distributions of power on patterns of diffusion, but with the exception of Steeves's (1990) work, there has been little emphasis on the interplay between gender, power, and diffusion.

\section{Rapid Diffusion of the Tests}

A mass of evidence from research studies done by government agencies and voluntary organizations in India shows that sex determination tests, and particularly amniocentesis and chorion villa biopsy, have diffused rapidly in India. They were first introduced in 1975, when the All India Institute of Medical Sciences in Delhi ${ }^{1}$ and the Institute for Research in Reproduction in Bombay ${ }^{2}$ began to offer amniocentesis for the detection of fetal abnormalities 
(Kishwar 1987; "Sex Determination" 1988). It soon became apparent that couples were using the tests for determination of the sex of the fetus, and were subsequently aborting female fetuses. Both institutions closed their amniocentesis facility soon after this came to light.

The tests really took off around 1981, when a private clinic was opened in Amritsar, Punjab, by a physician trained in the United States, who openly advertised the use of amniocentesis for sex determination. Various clinics and hospitals followed suit, and the tests spread from Punjab to Gujarat, Maharashtra, Uttar Pradesh, Bihar, Madhya Pradesh, Punjab, Tamil Nadu, and Rajasthan, and from big cities in these states to small towns and villages (Kishwar 1987). In 1984, the Times of India took notice and reported that between 1978 and 1983, around 78,000 female fetuses were aborted after sex determination tests in India (Parikh 1990). Patel (1989b) notes that the names of the techniques-sonography, fetoscopy, needling, chorion villa biopsy, and amniocentesis - have become "household words" in urban India.

The greatest mass of evidence comes from Bombay, mainly because of the concerted and organized research efforts of activists in this city. By 1988, Bombay had approximately 200 sex determination clinics (Sarin, Tellis, Chatterjee, and Sarkar 1988). ${ }^{3}$ In fact, it is estimated that approximately half of all abortions in Maharashtra state in 1987 were sex-selective abortions (Parikh 1990). ${ }^{4}$ According to another estimate by a group of doctors, between 30,000 and 50,000 female fetuses were aborted in Maharashtra state in 1986-87 (Forum against Sex Determination and Sex Preselection [Forum] 1991). ${ }^{5}$ A government committee formed in 1986 to investigate the reach of the test in Bombay found that of the forty-two doctors interviewed, 84 percent were performing amniocentesis for sex determination tests. These doctors were found to perform, on an average, 270 amniocentesis tests per month. It was also found from this study that women from all classes, but predominantly middle-class and lower-class women, go for the tests (Patel 1989b).

Nationally, the clientele for the tests spans from urban slum dwellers to workers in multinational companies. The tests cost anywhere between Rs 70 and Rs 500 (about $\$ 6$ to $\$ 40$ at the time the evidence was gathered), and the price continues to come down, to accommodate various classes (Patel $1989 \mathrm{~b}$ ). The poor are willing to stretch their resources to avail of the tests. Marginal farmers and landless laborers in some areas are paying 25 percent compound interest on loans from money lenders to pay for the tests.

Not only are the tests becoming more widely available by the day in several cities and towns in various states of India, but also in the rural areas, through collection centers that send the samples of amniotic fluid through courier service to laboratories in the cities. In fact, in one backward tribal district of Maharashtra state, where potable water and electricity do not exist, 
and where the rural health centers do not have cold storage facilities for oral polio vaccine, amniotic fluid in ice packs was being sent routinely to Bombay for analysis (Forum 1991).

The tests have diffused rapidly despite (a) denouncements by the central government, (b) legislation banning the tests in Maharashtra (of which Bombay is the capital), and (c) all the publicity and lobbying efforts of activists engaged in legislating a nationwide ban of the tests and in raising consciousness about its deleterious effects. ${ }^{6}$

Since the tests were banned for the purpose of sex determination in Maharashtra in 1988, they have gone underground, but continue to be offered widely (Shivdasani 1989). ${ }^{7}$ In anticipation of better enforcement, doctors in Maharashtra are gearing up to offer suitable alternatives, such as highresolution sonography, sex selection, or simply charging higher prices and keeping no records (Menon 1989). Also, since the ban was put into place in Maharashtra, the tests have burgeoned in the neighboring state of Gujarat (Mehta 1989). This speaks clearly to the endurance of sex determination techniques in the Indian context.

\section{Reasons for Diffusion}

The sex determination tests offer a definite relative advantage over previous methods available to predict the sex of the fetus. The immediate predecessors of the tests are folk theories that help predict the sex of the fetus, having to do with the positioning of the fetus in the stomach, the shape of the stomach and pelvic area of the pregnant woman, the shape of the hairline of the stomach of the pregnant woman, and the general facial appearance and state of health of the pregnant woman (Sangari 1989). Undoubtedly, the sex determination tests provide a far more reliable and accurate prediction of the sex of the fetus than do the folk theories - they impart knowledge of the sex of the fetus, a knowledge that is highly valued in the Indian context.

This accurate prediction enables adopters to selectively abort the female fetus. ${ }^{8}$ The selective abortion itself may be positioned against earlier ways of dealing with an unwanted daughter, such as infanticide, or neglect through inadequate nutrition and health care. Selective abortion offers the advantage of carrying less social censure and of being harder to detect and prosecute (even if national legislation banning the use of the tests for sex determination is introduced) than infanticide. ${ }^{9}$

Knowledge of the sex of the fetus is highly valued within Indian society for several reasons. Son preference is deeply embedded within most commu- 
nities in India (Kumari, Singh, and Dubey 1990; Lahiri 1974; Miller 1981; Patel 1989b; Sangari 1989; Wyon and Gordon 1971). Sons are desired for their economic, social, and religious value. This son preference reflects the general devaluation of women in the Indian context. Women are viewed as less productive than men, and whatever assets they have are transferred to the groom's family at the time of marriage. In addition, partly because of the low value attributed to females, the girl's family is forced to pay a dowry (usually beyond its means) to the boy's family in order to get her married. Because of their general superior status, boys are also more valued socially. Parents of boys receive the admiration and approval of their family and community, whereas parents of girls are generally pitied. Moreover, boys are required to perform the religious rites on their parents' death; they are a gateway to heaven (Shukla and Kulkarni 1986).

Historically, the devaluation of women has resulted in female infanticide and neglect through inadequate nutrition and health care (Kumari, Singh, and Dubey 1990). Infanticide and neglect in turn have been partly responsible for a negative female to male population ratio in India since 1872 (when the first modern census was taken). India is one of the few countries in the world with fewer females than males. Even more significant is the steady decline in this ratio since 1901, and an especially sharp decline since 1961 (with a slight rise in 1981) (Kishwar 1987; Mies, Bennholdt-Thomsen, and Werlhof 1988; Roggencamp 1989). ${ }^{10}$ Kishwar and Mies both relate the decline to the deleterious effects of the spread of capital-intensive agriculture and industry. Women have lost ground to men both in terms of employment in agriculture and industry, and in terms of the ownership of land.

Both women's worsened economic condition and the general spread of consumerism have led to the spread of dowry to communities and classes that previously did not practice it. This, in turn, had led to the further devaluation of women and the reinforcement of son preference (Arora and Desai 1990).

It is in this context that any technology that allows parents to either predict the sex of the fetus and selectively abort the female fetus, or select the sex of the fetus, is welcomed by almost everyone. ${ }^{11}$ This nearly universal demand for the technology in turn has motivated several doctors to open clinics all over the country, and to advertise their services widely. ${ }^{12}$ The advertisements have worked in tandem with word of mouth to fuel the rapid spread of the tests. Both the profit potential of the tests and their compatibility with the Indian social, economic, and ideological fabric, then, have insured rapid diffusion across state, class, caste, and community lines. The doctors themselves have found ample moral justification for sex determination in ideolo- 
gies of free choice (the women themselves opt for the tests), social service (the women are relieved of great stress and sometimes ill-treatment by avoiding the birth of a daughter), and family planning (every couple has an obligation and right to plan their family). ${ }^{13}$

Selective abortion itself is also highly compatible with Indian society. Parents are used to giving blatantly favorable treatment to boys, and this can easily be extended to the fetus. Abortion does not carry a stigma in most Indian communities, and the Indian government has made abortion legal on broad grounds, and has sought to make it widely available. In the cities, a woman can generally get an abortion for Rs 75 to Rs 80 (about $\$ 7$ at the time) (Joshi 1986). ${ }^{14}$

In the end, compatibility appears to be the deciding factor in adoption, outweighing other considerations. In fact, compatibility with the social system ensures diffusion despite legal barriers, costs, and inconveniences. As was mentioned earlier, laborers are taking loans at high interest rates to avail of the tests, and sometimes they travel great distances to have the test done.

\section{Contestation over Meanings}

Beyond compatibility with the social structure, the meaning of the innovation within a particular social system is of utmost importance in its diffusion. In the case of the sex determination tests, the particular use to determine the sex of the fetus had a compelling force within Indian society that can only be explained by the institution of son preference. The use of the test to detect genetic abnormalities did not have equivalent force in the Indian context. In fact, most adopters of the test have no idea of its capability to detect abnormalities (Forum 1991). It was not until the tests became explicitly linked with sex determination that their popularity soared. It was with the revelation of a particular kind of information that had loaded meaning in the Indian context-the sex of the fetus-that the tests took hold within India.

The ideology of son preference in India is continually perpetuated through rituals and folklore. At wedding ceremonies, it is common to perform rituals signifying fertility in general, and the birth of sons in particular. A common blessing is, "May you become the blessed mother of eight sons." The birth of a baby girl is mourned in almost every family, while the birth of a boy is greeted with conch shells and sweets (Forum 1991). The ideology of son preference is so deeply embedded within commonsense understandings that when asked how many children they have, couples often will mention only the number of sons. 
It is mainly in the arena of meanings that activists working to impose a ban on the use of the tests for sex determination (chief among them the Forum against Sex Determination and Sex Preselection in Maharashtra), have waged most of their battles. In attempting to educate the general population of the long-term implications of the use of the tests, they have written songs and made films that highlight the discrimination between boys and girls. They have also organized fairs and skits (short, informal plays) that emphasize equality between girls and boys, and that enact role reversals, with boys cooking and girls washing cars, and so on. They have organized demonstrations in which prominent parents with only daughters marched proudly with them, and in which schools have shouted slogans such as, "ladki na ladke se kam" (girls are in no way inferior to boys) (Forum 1991). They have used the press, cinema, and alternative media extensively to disseminate their own understandings of the causes and consequences of son preference and the use of sex determination tests. By doing so, they have attempted to rearticulate embedded notions about daughters and sons.

The activists have also systematically rebutted every argument presented in favor of the tests by doctors and academics. They have shown the fallacies and the inconsistencies in the arguments regarding free choice (women opt for the tests themselves), family planning (a couple has the right to have a balanced family), population control (limiting unwanted daughters will bring the actual number of children closer to the desired number of children), and supply and demand (limiting the supply of girls and/or women will improve their status in the long run). ${ }^{15}$

But even if the women's groups and their allies eventually succeed in raising consciousness among a significant proportion of the population, they still have to contend with the stubborn material underpinnings of son preference, especially the spread and the intensification of the dowry system. It is as much the material aspects of the spread of capitalism, and with it consumerism and the dowry system, as the ideological aspects of son preference and woman devaluation, that continue to lend great force and effectuality to advertisements such as "Better 500 Rupees now than 5000 Rupees later," or "Better to pay the cost of sex determination test plus abortion now than to pay a dowry later."

\section{Lessons for Diffusion Research}

The quick adoption of the sex determination-selective abortion technology by almost all sectors of the Indian population forcefully supports the thesis that, when particular technologies fit and reinforce the major power 
structures, including normative structures, of a society, they will be adopted regardless of built-in resistances or predispositions toward change as represented by technology. When an innovation compellingly answers people's present needs (in this case, economic, social, and religious needs), it will almost spontaneously diffuse through a society, through market channels, and it will even close socioeconomic gaps. Further, innovations that are highly compatible with traditional institutions, especially traditional patriarchal institutions, will diffuse rapidly, and they will diffuse despite obstacles.

This case also helps illuminate the connections between new technologies, modernization, and women's situation. In various ways within the Indian context, modernization has enmeshed comfortably with traditionalism to further devalue and dehumanize women. New technologies and systems have often been a part of this process of squeezing women between tradition and modernity. The introduction of capital-intensive technologies in agriculture and industry has displaced large numbers of women workers. Heightened consumerism has led to the worsening and spread of the dowry custom; the groom's family now wants watches, video recorders, scooters, ovens, whatever new gadgets they can obtain from the bride's family to enhance their social status. The spread and intensification of dowry has, in turn, fueled the demand for sex determination and sex selection tests. In the age of consumerism, girls have become more expensive than before (Shukla and Kulkarni 1986). As Patel (1989b) says, "The uncontrollable lust of consumerism and the commercialization of human relations have combined with patriarchal power over women to reduce Indian women to easily dispensable commodities" (p. 6). To borrow Elson and Pearson's (1984) term, the diffusion of certain technologies within a particular social system tends to "intensify the existing forms of gender subordination" (p. 31). The diffusion of sex determination tests with the concomitant diffusion of selective abortion, for instance, reinforce son preference and woman devaluation. They further legitimize the ill-treatment of girls and women, and the perception of women as male-producing machines.

This case also suggests that it may be as important to study the diffusion of potentially harmful technologies as it is to study the diffusion of technologies that are considered to be beneficial. It is no coincidence that women's groups and people's science groups in India, as well as various women's groups all over the world, have been more concerned with questioning the appropriateness of certain technologies and attempting to stem the diffusion of particular technologies than with overcoming resistance to adoption of technologies. From the perspective of those who have been historically denied control of technology, the question becomes one of understanding and directing the influx of technologies so they empower rather than further sub- 
ordinate the poor, particularly women in the marginalized classes. Ratcliff's (1989) concern when she says, "It is important that we question technological developments and the directions in which they are moving at their inception because a technological trajectory is difficult to redirect once it is established" (p. 3) is almost a direct echo of activists' concerns regarding technology in India (Patel 1989b; Ravindra 1986, 1987).

That technological trajectories can be stubborn is evident from the sex determination case, as well as at least a few other instances. The diffusion of the infant milk formula in various Third World countries is another classic example. It was aggressively marketed in the 1970 s by multinational food companies, and was readily adopted by large numbers of families in Latin America and Asia. Projected as nutritionally superior to breast milk, and perceived as a status symbol, its use spread rapidly, with serious effects on children's health (Harrison 1981). Intrauterine devices (particularly the Dalkon Shield), injectables, and implants have also been aggressively promoted in Third World countries, and have posed a health risk for large numbers of women (Yanoshik and Norsigian 1989). Organized efforts to stem the spread of these technologies, or to restrict their diffusion, have made some headway. The infant milk formula is not as aggressively and visibly promoted as it used to be, and A. H. Robins Company was forced to file bankruptcy and to remove Dalkon Shields from the market. Yet the infant milk formula continues to be marketed in many countries, and intrauterine devices, injectables, and implants continue to be promoted. Antidiffusion efforts are up against various obstacles, including multinational companies that benefit from marketing these products in the Third World. In the case of birth control technologies, activists must also contend with population control agencies and sometimes with their own governments.

Another example comes from the United States. Kunisch (1989) shows persuasively how electronic fetal monitors (EFMs) were successfully marketed and became widely adopted throughout hospitals in the United States, despite a lack of evidence regarding their benefits for the laboring mother or the infant. The rapid diffusion of the monitors resulted from savvy marketing by Corometrics Systems, Inc., and from their compatibility with the technologically intensive health care system. Further, the monitors provide a "paper trail" for insurers of both doctors and patients, and can be used as evidence in malpractice suits. They are, therefore, compatible with the insurance system in the United States. The monitors have also enabled doctors to regain control over birthing, control that had been threatened by childbirthing movements such as the Lamaze method, home delivery, and so on. For all these reasons, use of the monitors was well entrenched by the mid-1970s, when controversy over the technology emerged. Studies in the 1970s showed 
that widespread use of EFMs had resulted in an increased rate of cesarean sections and postpartum infections. By the early 1980 s, most studies had shown that EFMs presented no clear benefit for low-risk deliveries. By the time the evidence was gathered, however, the technology was too well established to reverse the trend and to restrict the use of EFMs to only high-risk deliveries.

In the Indian case, like the other cases presented, antidiffusion efforts have to contend with the profitability factor. But even more so, they have to contend with eager adoption of the tests by the people themselves. This brings to light a central dilemma posed by the Indian case. When large numbers of people within a population voluntarily opt to use particular technologies, do we have the right to interfere? Must we not respect individual adoption decisions? The answer to these questions hinges on the way in which individual adoption decisions are understood within a particular context. In the case of the diffusion of the tests, it is clear that individual adoption decisions cannot be interpreted in any straightforward sense as just that. Rather, adoption decisions are made within a certain social fabric, and whether there is direct coercion involved or not, the decision cannot be adequately understood unless its social context is fully grasped. The Forum in India grappled with just this question when deciding whether to take legal action against the tests. Their decision rested on their interpretation of the authenticity of Indian women's decision to adopt the tests. The Forum came down decisively in favor of a ban of the tests for the purpose of sex determination based on the following reasoning:

Repeatedly it has been stated that women themselves enthusiastically welcome the test and feel that it is a question of their having the right to choose. But are these choices made in a social vacuum? These women are socially conditioned to accept that unless they produce one or more male children they have no social worth. They can be harassed, taunted, even deserted by their husbands and relatives if they fail to do so. Thus their "choices" depend on fear of society. (Patel 1989b, 7)

In addition, it is apparent that the spread of the tests endangers women's health and further devalues them in the long run. ${ }^{16}$ In view of these factors, it is entirely appropriate for both voluntary organizations and the government to use their power and resources to undercut the legitimacy of the tests and to actively stem their adoption, as they are currently doing. But it is even more important, and the activist groups in India are keenly aware of this, to use all means to change both the material and the ideological underpinnings of son preference within the Indian context in the long run. And it is appropriate for those of us outside India to support these efforts. 


\section{Notes}

1. Delhi is the capital city of India, and a major metropolitan center.

2. Bombay is a major metropolitan city in India. It is a major industrial and trading center. It is also India's major port city and the capital of the state of Maharashtra.

3. In the state of Maharashtra, the number of sex determination clinies rose from 10 in 1982 to $500-600$ in 1986 (Ravindra 1987).

4. This translates into about one-sixth of all conceptions resulting in sex-selective abortion.

5. There is no nationwide statistical analysis of the relationship between the rise in the use of sex determination techniques and abortion rates, and there are no data on sex-selective abortion trends nationwide. Some statistics on abortion rates in India are available, and they suggest a steady, gradual increase in abortion rates from 1972 to 1987 (Henshaw and Morrow 1990). But it is impossible to draw generalizations about the influence of the use of the tests from these data. There are various small-scale studies, and overwhelming anecdotal evidence, leading to the undeniable conclusion that the tests are used mainly to detect and to abort female fetuses, and, therefore, their rapid spread necessarily implies a massive increase in sex-selective abortions. For example, for more than one thousand female fetuses discovered in a Bombay hospital and later aborted elsewhere, only one male fetus was aborted selectively (Shukla, Kulkarni, and Patel 1987).

6. For detailed accounts of the legislation passed in Maharashtra, its provisions, penalties, and loopholes, see Singh (1986a, 1986b) and Parikh (1993).

7. Immediately after the passage of the Maharashtra Regulation of Use of Pre-Natal Diagnostic Techniques Act of 1988, the number of sex determination clinics went down, and overt advertising of the tests was curbed. Most clinics, however, simply went underground (Parikh 1993). There is some indication that the price of the tests has gone up to about $\$ 750.00$ as a result of the new law, which would restrict its use to well-to-do families (Wertz and Fletcher 1989).

8. The diffusion of the sex determination technology is inextricably tied to the advent of sex-selective abortion. Earlier folk methods simply did not have the level of accuracy required to take the next step of aborting the unwanted fetuses. With the low accuracy associated with folk methods, the risk of mistakenly aborting male fetuses was simply too high, and, therefore, the option of sex-selective abortion did not exist.

9. Although infanticide has been outlawed in India since 1870 , it is still practiced in some villages in India, especially by the poor. Its widespread existence in a few villages in the states of Tamil Nadu and Rajasthan has been recorded in the late 1980s. Those who still resort to female infanticide in the villages normally cannot afford, or do not have access to, sex-selective abortion (Bumiller 1990). For those who can afford sex-selective abortion, it may be seen as a legal alternative to infanticide (Viswanathan 1991).

10. The 1991 census of India reported a ratio of 929 females to 1,000 males (Basu 1991). In 1901, the ratio was 972 females to 1,000 males, and in 1961, the ratio was 941 females to 1,000 males (Mies, Bennholdt-Thomsen, and Werlhof 1988).

11. In fact, sex selection techniques, techniques that are designed to influence the sex of the child at conception, are also gradually gaining ground in the Indian context (Patel 1989a).

12. Although the price for the tests varies greatly, doctors in private clinics in Bombay charge as much as $\$ 125$ for the test. For many doctors, the tests are a lucrative part of their business (Bumiller 1990).

13. It should be clarified that not all doctors support the tests, and even among those who offer them, some express moral qualms. Although many doctors are complacent about offering 
the tests, many others offer them reluctantly, out of concern for the woman's well-being. Still other doctors, particularly young woman doctors, are strongly opposed to the test (Arora and Desai 1990).

14. This is in no way intended to suggest that abortion should not be available on broad grounds to Indian women. This point is being made here simply to show the general compatibility of the tests with various facets of the Indian system.

15. To the argument that women's status may be enhanced if their supply is reduced, Forum activists appropriately respond that India has had a negative and declining female-male ratio for almost a century, and their status certainly does not seem to have improved-if anything, health and economic indicators show that their condition has worsened overall. For a summary of the arguments for the use of the tests, and the major rebuttals by Forum activists, see Patel (1989b) and Parikh (1990).

16. The deleterious effects of the tests and of repeat abortions on Indian women's health could be significant in light of the generally high rates of matemal mortality in India. India has one of the highest maternal mortality rates in the world, at about 460 per 100,000 births (Parikh 1993; Ramachandran 1988). It has also been reported that septic abortion (abortion resulting in serious infection) is the cause of 20 percent to 30 percent of all maternal deaths in India (Ramachandran 1988). In addition, the use of the tests encourages both delayed and repeat abortions, and both factors have been shown to substantially increase the incidence of morbidity and mortality associated with induced abortion in India.

\section{References}

Arora, U., and A. Desai. 1990. Sex determination tests in Surat: A survey report. Manushi 60:37-38.

Basu, A. M. 1991. Why the female ratio is falling. Times of India, 1 June, 12.

Bumiller, E. 1990. May you be the mother of a hundred sons: A journey among the women of India. New York: Fawcett Columbine.

Elson, D., and R. Pearson. 1984. The subordination of women and the internationalization of factory production. In Of marriage and the market, edited by $\mathrm{K}$. Young, C. Wolkowitz, and R. McCulagh, 18-40. London: Routledge and Kegan Paul.

Forum against Sex Determination and Sex Preselection (Forum). 1991. The campaign against sex determination and sex pre-selection in India - our experiences. In Declaration of Comilla: Proceedings of FINRRAGE-UBINIG international conference 1989, edited by F. Akhter, W. V. Berkel, and N. Ahmed, 156-64. Bangladesh: Unnayan Bikalper Niti Nirdharoni Gobeshona: [UBINIG].

Harrison, P. 1981. Inside the Third World: The anatomy of poverty. 2nd ed. New York: Penguin Books.

Henshaw, S. K., and E. Morrow. 1990. Induced abortion: A world review: 1990 supplement. New York: The Alan Guttmacher Institute.

Joshi, G. V. 1986. Will women become an endangered species? Deccan Herald, 31 August.

Kishwar, M. 1987. The continuing deficit of women in India and the impact of amniocentesis. In Man-made women: How new reproductive technologies affect women, edited by G. Corea, R. D. Klein, J. Hanmer, H. B. Holmes, B. Hoskins, M. Kishwar, J. Raymond, R. Rowland, and R. Steinbacher, 30-37. Bloomington: Indiana University Press.

Kumari, R., R. Singh, and A. Dubey. 1990. Growing up in rural India: Problems and needs of adolescent girls. New York: Advent Books. 
Kunisch, J. R. 1989. Electronic fetal monitors: Marketing forces and the resulting controversy. In Healing technology: Feminist perspectives, edited by K. S. Ratcliff, M. M. Ferree, G. O. Mellow, B. D. Wright, G. D. Price, K. Yanoshik, and M. S. Freston, 41-60. Ann Arbor: University of Michigan Press.

Lahiri, S. 1974. Preference for sons and ideal family in utban India Indian Journal of Social Work, Bombay 34:323-36.

Mehta, G. 1989. Gujarat tops in female foeticide. Times of India, 4 February, 1, 11.

Melkote, S. R. 1991. Communication for development in the Third World: Theory and practice. Newbury Park, CA: Sage.

Menon, M. 1989. SD tests continue despite ban. Midday (Bombay), 14 May, 4.

Mies, M., V. Bennholdt-Thomsen, and C. V. Werlhof. 1988. Women: The last colony. London: Zed Books.

Miller, B. D. 1981. The endangered sex: Neglect of female children in rural North India. Ithaca, NY: Cornell University Press.

Parikh, M. 1990. Sex selective abortions in India: Parental choice or sexist discrimination? Feminist Issues, 10:19-32.

. 1993. The morass of sex selective abortions: Legal inefficiency and the continued tragedy of unwanted daughters in India. Paper read at 45th Annual Meeting of the Association of Asian Studies, 28 March, at Los Angeles, California.

Patel, V. 1989a. Sex tests endanger women's rights. The Times of India (Bombay), 14 January. $1989 \mathrm{~b}$. Sex-determination and sex-preselection tests in India: Modern techniques for femicide. Bulletin of Concerned Asian Scholars 21:2-10.

Ramachandran, P. 1988. India. In International handbook on abortion, edited by P. Sachdev, 235-50. New York: Greenwood.

Ratcliff, K. S. 1989. Introduction. In Healing technology: Feminist perspectives, edited by K. S. Ratcliff, M. M. Ferree, G. O. Mellow, B. D. Wright, G. D. Price, K. Yanoshik, and M. S. Freston, 1-10. Ann Arbor: University of Michigan Press.

Ravindra, R. P. 1986. The scarcer half. Bombay: Center for Education and Documentation. . 1987. Struggle against sex determination techniques: Unfinished battle. Economic and Political Weekly, 21 March, 490-92.

Rogers, E. M., ed. 1976. Communication and development: Critical perspectives. Beverly Hills, CA: Sage.

. 1983. Diffusion of innovations. Rev. ed. New York: Free Press.

Roggencamp, V. 1989. Abortion of a special kind: Male sex selection in India. In Test-tube women: What future for motherhood? Rev. ed., edited by R. Arditti, R. D. Klein, and S. Minden, 266-77. London: Pandora Press.

Roling, N. G., J. Ascroft, and F. W. Chege. 1976. The diffusion of innovations and the issue of equality in rural development. In Communication and development: Critical perspectives, edited by E. M. Rogers, 63-78. Beverly Hills, CA: Sage.

Sangari, K. 1989. If you would be the mother of a son. In Test-tube women: What future for motherhood? Rev. ed., edited by R. Arditti, R. D. Klein, and S. Minden, 256-65. London: Pandora Press.

Sarin, R., O. Tellis, P. Chatterjee, and M. Sarkar. 1988. Boy or girl? Sunday, 24-30 January, 13-18.

Sex-Determination and Female Foeticide: The Growing Menace. 1988. Health Monitor, 9 January, 6.

Shivdasani, S. 1989. No stopping prenatal sex determination tests. Deccan Herald (Bangalore), 25 February. 
Shukla, S., and S. Kulkarni. 1986. Social implications of sex-determination tests: Advances in medical field supporting backward social values. Mimeo.

Shukla, S., S. Kulkami, and V. Patel. 1987. Abuse of new technology. Seminar 331 (March): 14-17.

Singh, G. 1986a. Amniocentesis and the legal provisions pertaining to it. Paper read at a workshop organized by the Forum against Sex Determination and Sex Preselection Techniques, March, at Bombay, India. Mimeo.

1986b. Comments on the private bills presented in the Legislative Assembly (Maharashtra) and in the Parliament on amniocentesis. Paper read at a workshop on feminist perspectives on women, health and reproduction, December, at Bombay, India. Mimeo.

Steeves, H. L. 1990. Agricultural extension and African women. Development Communication Report 70:4-5.

Viswanathan, P. 1991. Limiting the license to kill. Sunday Times of India, 13 January, 7.

Wertz, D. C., and J. C. Fletcher. 1989. Fatal knowledge? Prenatal diagnosis and sex selection. Hastings Center Report 19 (May/June): 21-27.

Wyon, J. B., and J.E. Gordon. 1971. The Khanna study: Population problems in the rural Punjab. Cambridge, MA: Harvard University Press.

Yanoshik, K., and J. Norsigian. 1989. Contraception, control and choice: International perspectives. In Healing technology: Feminist perspectives, edited by K. S. Ratcliff, M. M. Ferree, G. O. Mellow, B. D. Wright, G. D. Price, K. Yanoshik, and M. S. Freston, 61-92. Ann Arbor: University of Michigan Press.

RASHMI LUTHRA is Assistant Professor of Communications at the University of Michigan-Dearborn. She has published articles on the social marketing of contraceptives, and gender issues in the immigrant Indian media in the United States. 